\title{
SLIPPED UPPER FEMORAL EPIPHYSIS
}

\author{
Characteristics of a Hundred Cases
}

\author{
H. JACKSON BURROWS, LONDON, ENGLAND
}

From the Institute of Orthopaedics, Royal National Orthopaedic Hospital, London and Stanmore

When the British Orthopaedic Association commissioned an investigation of the results of treatment of slipped upper femoral epiphysis, it seemed that this might be based more broadly than upon the results of a particular operation popular at the moment, and that the inevitable delay while patients remained under observation would provide an opportunity of studying the clinical characteristics of the disease, and subsequently relating them to the treatment and its results. Possibly a sound etiological classification might emerge, relating the clinical study of the disease to the notable laboratory results of Harris (1950).

To this end a detailed questionnaire was sent out, and the replies were coded on punch cards.

Against the obvious advantages of this method must be placed two disadvantages in particular. First, although every question on the forms is relevant, their completion is tedious, so that some questions go unanswered, and this seriously affects the statistical validity of the information collected from them; indeed some returns cannot be used at all, and so the cases are not consecutive. The other most important disadvantage is that the bother of returning a comprehensive form dissuades many from collaborating, or of collaborating for long, and so diminishes the number of cases for investigation. Everyone, except those who live by them, is tired of forms.

A hundred straightforward cases have been reviewed. A few oddities that have been excluded are mentioned at the end.

\section{SEX, AGE AND SIDE AFFECTED}

Sex-The hundred patients comprise sixty boys and forty girls, but there may have been some selection because the cases could not be consecutive. Data have been tabulated for each sex separately, but are here reproduced collectively except when the figures differ much in the two sexes.

TABLE I

Sides Affected in Each Sex

\begin{tabular}{|c|c|c|c|}
\hline Side & Boys & Girls & Both sexes \\
\hline Right only . & 15 & 14 & 29 \\
\hline Left only & 34 & 14 & 48 \\
\hline \multirow[t]{2}{*}{ Right and left } & 11 & 12 & 23 \\
\hline & 60 & 40 & 100 \\
\hline
\end{tabular}

Age-The age, in years, is at the time of first attendance. As in previous series, there is a striking difference in age between the boys, mostly fourteen to sixteen years old, and the girls,

VOL. $39 \mathrm{~B}$, NO. 4, NOVEMBER 1957 


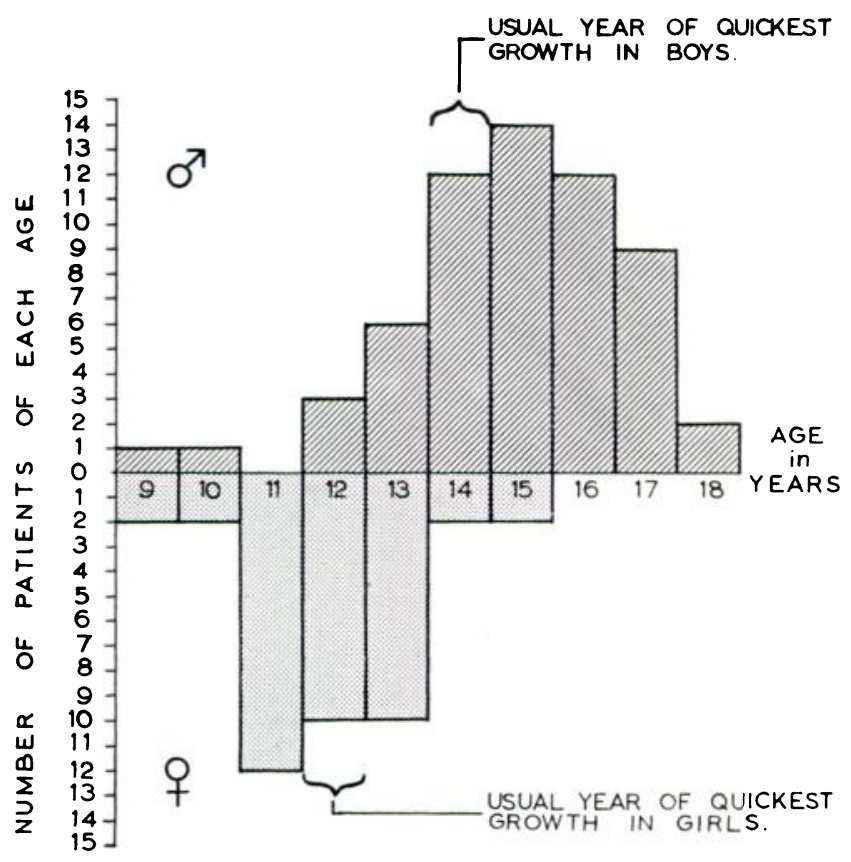

Fig. 1

The number of patients of each age at the time of first attendanceboys above the base line, girls below.

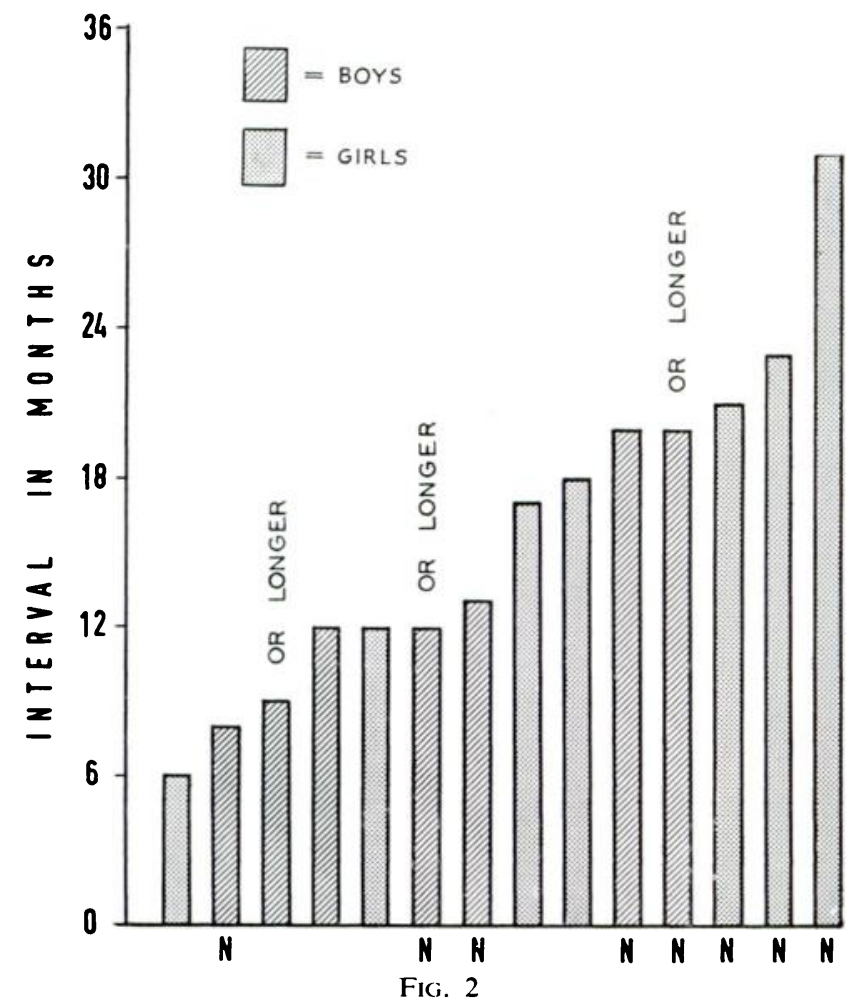

The interval in months between slipping on the first side and slipping on the other side in fourteen of the twenty-three bilateral cases. Those indicated by the letter $\mathbf{N}$ showed no overweight or evidence of endocrine disturbance. The others did (including one case in which gradual slipping appeared to take place synchronously on the two sides). 
mostly eleven to thirteen. In other words, the girl is stricken at her preparatory or primary school and the boy at his public or secondary school. The median age in the girls is twelve, their usual year of most rapid growth; the median age in the boys is fifteen, about a year later than their usual year of most rapid growth (Fig. 1).

Side-In boys only the left side was more than twice as often affected as the right (Table I). Both hips were affected in eleven boys and twelve girls.

In one boy aged fourteen years and ten months, abnormally fat, gradual slipping seemed to begin in both hips synchronously, but in all the other patients there appeared to be an interval between slipping on one side and slipping on the other, varying from six months to two years or, in one case, as long as thirty-one months (Fig. 2). Consequently, unless a series of cases is followed for long enough, some that will ultimately become bilateral are recorded as unilateral. Eleven of these twenty-three cases were recorded as one-sided until Mr John Hall's follow-up revealed that the second side had subsequently suffered.

Affection of both hips suggests a constitutional cause, which might have the effect of weakening the bonds of the epiphysis or increasing its burden. Attempts to correlate bilaterality with weight and endocrine function are recorded later.

\section{EVIDENCE OF NUTRITIONAL AND ENDOCRINE FACTORS}

Diet-The ascorbic acid excretion test was carried out in six patients. It was normal or nearly so (not more than 50 milligrams required for saturation) in four. It was decidedly low in one patient without evident dietetic fads. It was very low in one patient who, although taking a scorbutic diet without any vegetables at all, showed no clinical evidence of scurvy. Otherwise dietetic fads have been rare, but overfeeding was possible.

Physique - It was remarkable how many hospitals accepting children for prolonged treatment failed to record heights and weights of their charges. Nevertheless the height was recorded in sixty-three children and the weight in sixty.

To make any collective use of these data it is necessary to relate each child's height or weight to that of a normal child of the same age and sex by allotting an index of height (H.I.) or index of weight (W.I.).

Sutcliffe and Canham (1950) prepared tables of height and weight based on measurements made in 1948 of about 17,000 representative boys and girls from scattered areas of rural and urban England. From these tables they prepared indices by which the height (or weight) of a particular child can be compared with that of other children of the same sex and age; that is to say where he (or she) would come among a hundred such children arranged in order of height or weight, if indeed he came within their range at all.

Height-Figure 3 shows the result of preparing such indices of height for the thirty-five boys and twenty-seven girls whose height was recorded. The indices are plotted horizontally, and the number of children in each range is plotted vertically. The heavy outline shows the distribution expected in the same number of normal children: 10 per cent expected to have indices between 65 and $81 ; 15$ per cent between 81 and $90 ; 50$ per cent between 90 and 110; 15 per cent between 110 and 119; and 10 per cent between 119 and 135. Most of the sixty-two patients come within the expected range of height for sixty-two normal children of their age, but fewer patients are smaller than the average for their age and more are taller, though still within the normal range for their age. In other words, fewer are unusually short and more are unusually tall. Three girls have height indices above any in the normal range, and these patients can appropriately be described as not merely unusually tall, but abnormally tall. Figure 4 shows the figures for boys and girls more clearly differentiated, boys above the base line and girls below it.

VOL. 39 B, NO. 4, NOVEMBER 1957 


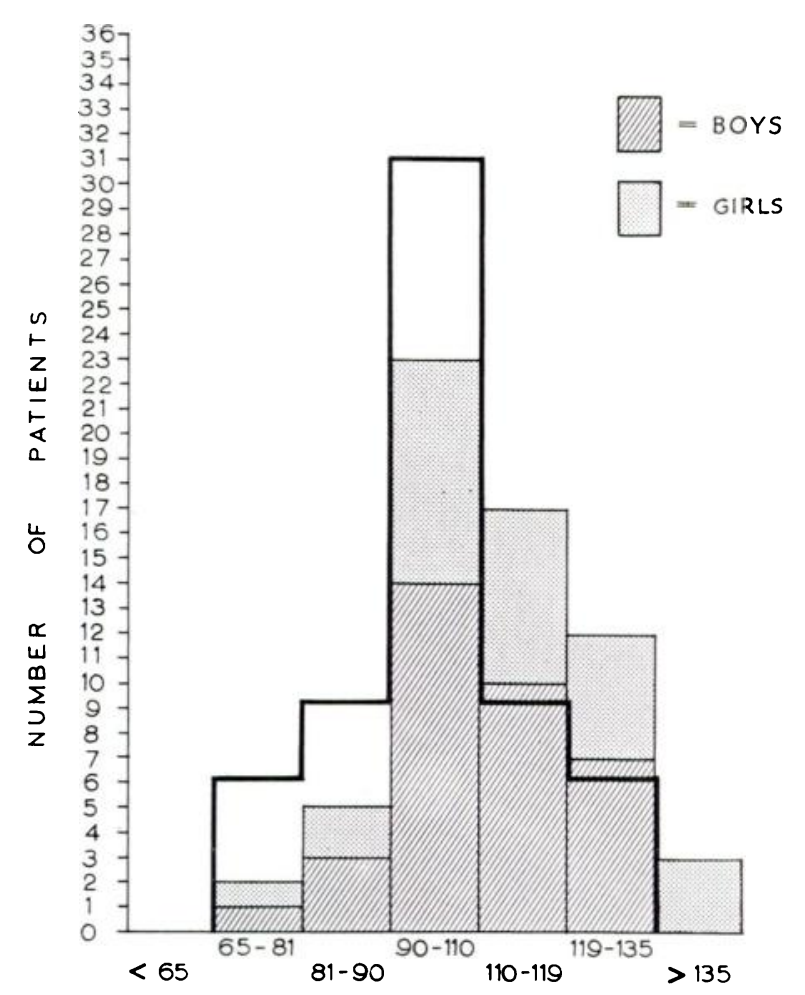

FIG. 3

The index of height for the sixty-two patients whose height at the outset was recorded. The expected indices for an average sample would be enclosed by the heavy outline.

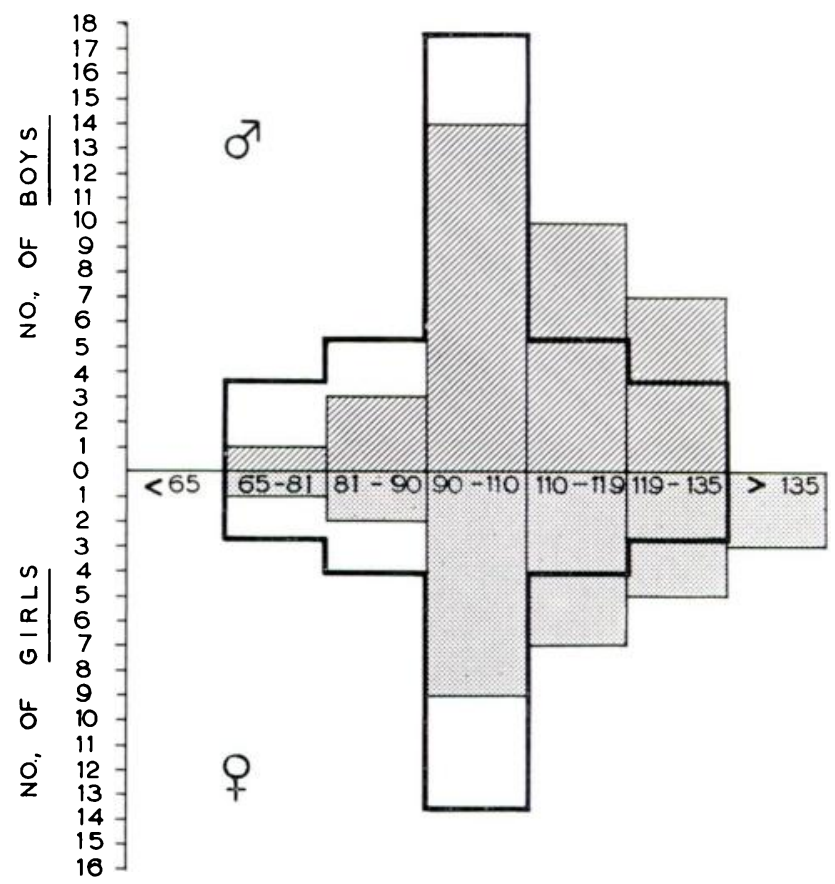

Fig. 4

As Figure 3, but with the data for boys plotted above the base line and for girls below it.

THE JOURNAL OF BONE AND JOINT SURGERY 


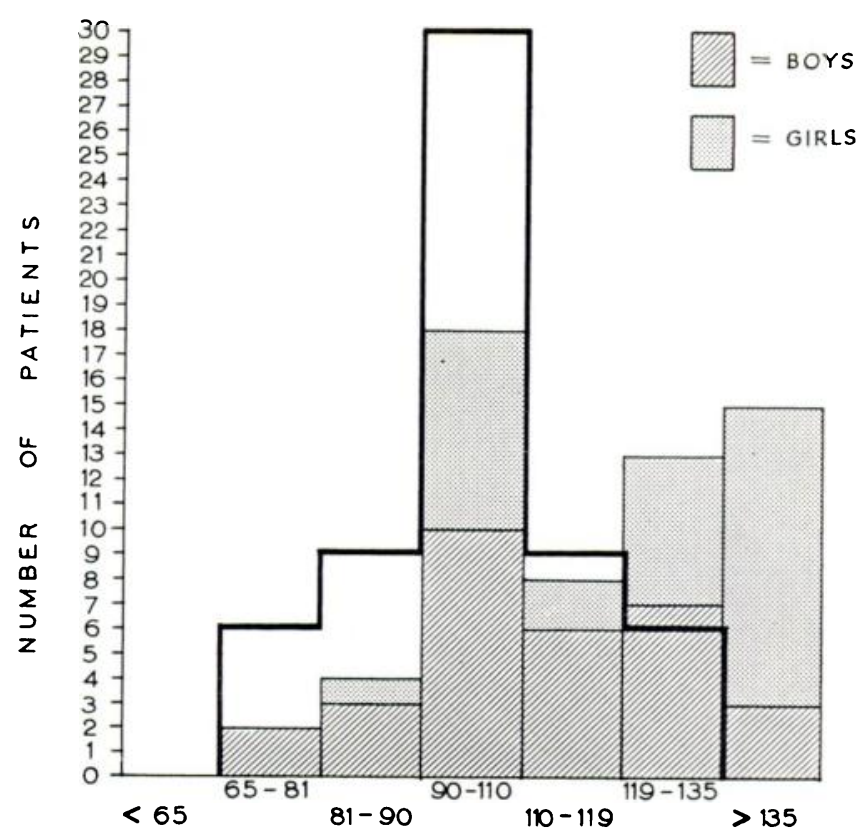

Fig. 5

The index of weight for the sixty patients whose weight was recorded, set out like the index of height in Figure 3.

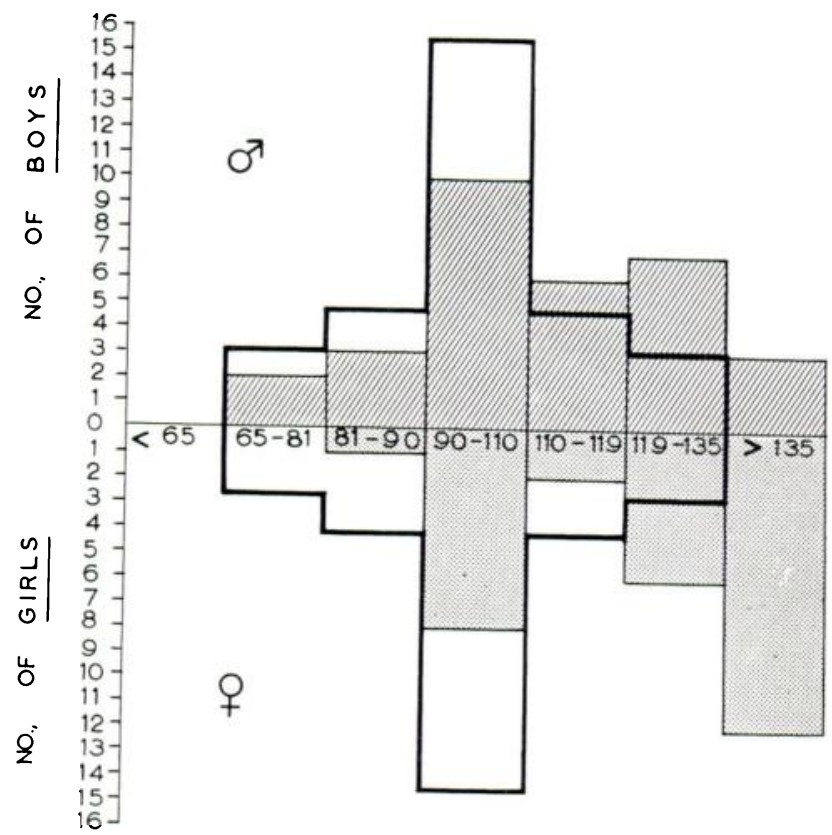

FIG. 6

As Figure 5, but plotted as in Figure 4, with boys shown above the line and girls below it.

VOL. 39 B, No. 4, NOVEMBER 1957 


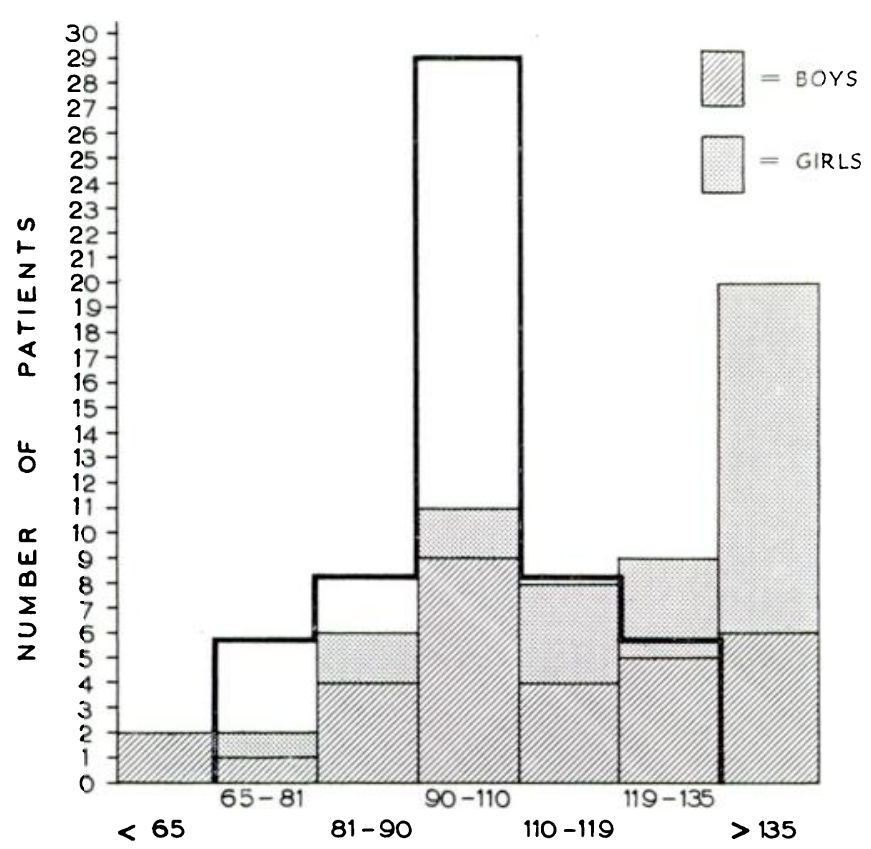

FIG. 7

The index of build (weight in relation to height) of the fifty-eight patients for whom the data were available, set out like the indices of weight and height in Figures 3 and 5.

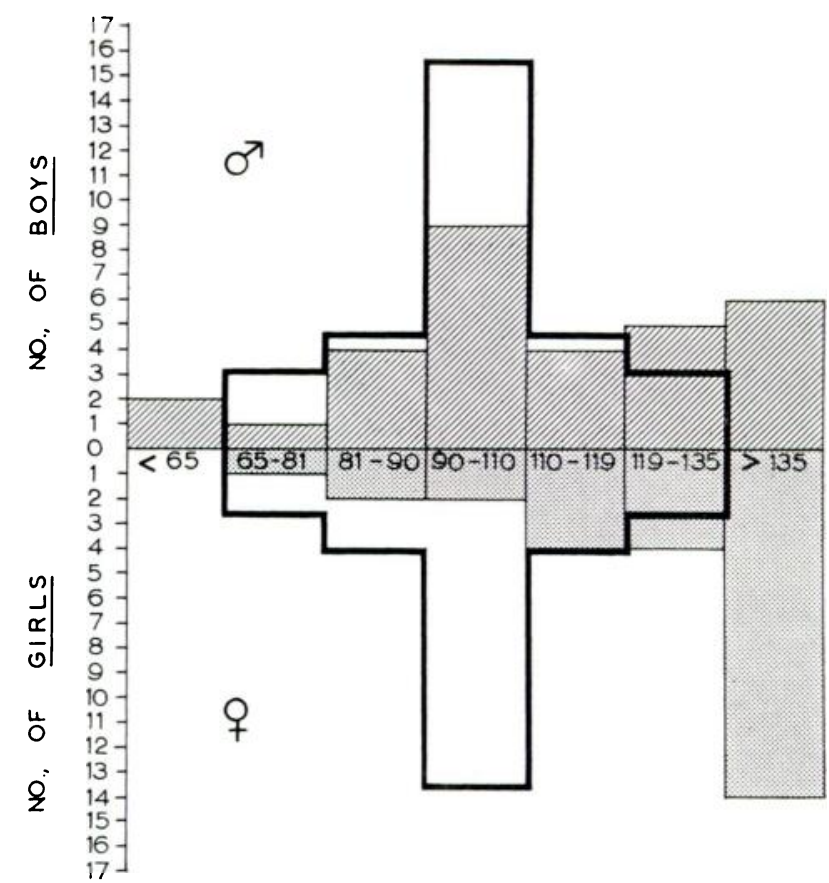

FIG. 8

As Figure 7, but set out like Figures 4 and 6, with boys shown above the line and girls below it. 
Weight-Figures 5 and 6 are similar diagrams for indices of weight of the thirty-one boys and twenty-nine girls who were weighed. The deviation from the outline expected from plotting the same number of normal children is much greater in this instance than in the similar diagrams for index of height. The excess of unusually heavy and of abnormally heavy (index over 135) is much more pronounced than the corresponding excesses of tall people. In fact two somewhat overlapping groups emerge: 1) To the right a large group of overweight children, many of them abnormally heavy (index over 135) and others merely swelling the numbers of those unusually heavy; 2) a group of children normally distributed as to weight provided the group is shorn of the abnormally heavy and some of the unusually heavy comprising group (1).

The distribution of the readings of the index of weight does not admit of any ready explanation except the existence of two distinct groups of patients, one comprising those of average weight for their age and another comprising those who are overweight, with perhaps about an equal number in each.

A similar explanation is possible for the distribution of the index of height, but with much more uncertainty.

Weight in relation to height (build) - By the use of indices we can go further than relate the height of a child to the expected range in a hundred normal children of the same sex and age, or alternatively do the same for weight: from the height and weight indices an index can be prepared that in effect relates the weight of the child to the expected range of weights among a hundred children of the same sex, age and height. This is known as the Index of Physique or, better, the Index of Build (B.I.). It has been possible to compute this for thirty-one boys and twenty-seven girls, and the results are shown in Figures 7 and 8 . The index of build exaggerates the grouping found for weight, and there emerge 1) a group of the unusually and abnormally sleek and 2) a group of normal build, and also seemingly a very small third group 3) of the abnormally lean or underdeveloped. This was made up of two boys with one-sided non-traumatic slipping. One was fifteen and three-quarters years of age, 5 feet $5 \frac{3}{4}$ inches in height, and only 6 stones $10 \mathrm{lb}$. (94 lb. $=43$ kilograms) in weight; he had no evident endocrine defect and excreted 9.1 milligrams and 8.2 milligrams respectively of ketosteroids (as dehydroandrosterone) in twenty-four hours. The other boy, sixteen years of age, 5 feet 4 inches in height, 6 stones $4 \mathrm{lb}$. ( $88 \mathrm{lb} .=40$ kilograms) in weight, was considered to be of "Lorain type," with scanty pubic hair and slight widening of the lower radial epiphyses but a broken voice and a urinary ketosteroid excretion of 7 milligrams daily.

Comment-In so far as the data are correct, the indices of height and weight give a wholly reliable picture. The index of build should be accepted with greater reserve, because it depends upon a contestible formula: B.I. $=\frac{1}{2}(3$ W.I. - H.I. $)$.

Sexual development-Replies about the development of the sex organs and of secondary sexual characters have been vague and sometimes contradictory. Evidence of delay or arrest was said to be present in ten and possibly another five, and absent from seventy-three, but these figures are unreliable.

Menstruation-Information is available for thirty-eight of forty girls (Table II). Among twenty-eight who had slipping of only one epiphysis the menstrual state is unreported in two, two had begun to menstruate from five to fourteen months before, and the remaining twenty-four had never menstruated. Of twelve girls who had slipping of both upper femoral epiphyses, none had menstruated before the first side gave trouble and at least seven had still not menstruated when symptoms began on the other side; by then one had had a scanty flow one or two months before. It is not known whether the remaining four patients with slipping of the epiphyses on both sides had or had not begun menstruating when slipping on the second side began. Menstruation was reported in some patients to begin five or six months, a year or even three years after slipping of an epiphysis.

VOL. 39 B, NO. 4, NOVEMBER 1957 
It may be concluded that a girl who menstruates is almost immune from slipping of the upper femoral epiphysis.

TABLE II

Menstrual State in Relation to Onset of Slipping

\begin{tabular}{|lcccc|}
\hline $\begin{array}{c}\text { Hips } \\
\text { affected }\end{array}$ & $\begin{array}{c}\text { Number } \\
\text { of } \\
\text { patients }\end{array}$ & $\begin{array}{c}\text { Number } \\
\text { who had } \\
\text { menstruated }\end{array}$ & $\begin{array}{c}\text { Number } \\
\text { who had not } \\
\text { menstruated }\end{array}$ & $\begin{array}{c}\text { Menstrual } \\
\text { state } \\
\text { unknown }\end{array}$ \\
\hline One $\cdot$ & 28 & 2 & 24 & 2 \\
\hline Both. & 12 & 0 & 12 & 0 \\
First side & & 1 & 7 & 0 \\
Second side & & 0 & 4 \\
\hline
\end{tabular}

Urinary ketosteroid excretion is an index, of sorts, of androgenic activity. The twenty-four-hour excretion of 17-ketosteroids was estimated in twenty-four patients of the series-thirteen boys and eleven girls. The figures (Tables III and IV) are not very informative, because the range of " normal" is so wide.

Presence or absence of endocrine defect-We have tried to distinguish patients with possible endocrine imbalance from those not suspect.

In order to draw distinct dividing lines we arbitrarily ascribed to endocrine defect all patients labelled "Frölich" and the one patient labelled "Lorain" and all patients having an abnormally high (more than 135) index of build*; this is to say all those too heavy to be expected among a hundred normal children of the same age and height.

All heavy patients with an " unusual " (index of 119-135) but not "abnormal" weight were separately listed as overweight. These were children who would be among the heaviest ten of a typical hundred normal children of the same sex, age and height.

The dividing line between the two groups is quite arbitrary, depending really upon the degree of overweight, except when the notes gave a definite pronouncement. Even this was not wholly reliable without a knowledge of the surgeon's assessment of Frölich's syndrome.

It has been possible to make a list of constitutionally " normal" patients without any gross deviation of weight or any other evidence of endocrine defect.

We did not rely on such things as secondary sexual characters, unusually thick epiphysial plates or the urinary excretion of 17-ketosteroids, because standards at about the time of adolescence are so variable.

Three abnormally tall patients were encountered (besides the pituitary giantess reported in a separate section), so tall as to exceed the stature of all of a hundred typical normal children of the same age. Two of them were also overweight for their height.

There were twenty-seven children who could not be assessed for lack of data, but were probably nearly all constitutionally normal.

Table $\mathrm{V}$ suggests that endocrine defects were commoner in the girls, but the large number of boys whose condition could not be assessed makes the figures uncertain.

Rather unexpectedly, no striking relationship was found between constitutional factors and bilateral affection (Table VI), but, here again, the number of unassessed cases makes interpretation doubtful.

Epiphysial maturation-Control radiographs of wrist and hand (to be taken synchronously with that of another subject of like age and sex) were requested, to provide evidence of osteoporosis, retardation of ossific centres or thickening of epiphysial plates. Twenty-nine patients were so examined, with mainly negative results. Osteoporosis was found in two cases,

* All but two had a similarly abnormal index of weight. 
TABLE III

URINARY KeTOSTEROID EXCRETION-BOYS

\begin{tabular}{|c|c|c|c|c|c|}
\hline Patient & Age & Physique & $\begin{array}{l}\text { Type } \\
\text { of } \\
\text { slip }\end{array}$ & $\begin{array}{l}\text { Urinary ketosteroid } \\
\text { excretion } \\
\text { milligrams/24 hours }\end{array}$ & $\begin{array}{l}\text { "Normal" } \\
\text { for age }\end{array}$ \\
\hline K. B. & $12+\frac{1}{1 !}$ & Rather tall. Weight normal for height & $?$ & 74 & $3-10$ \\
\hline T. M. & 14 & S2- & G & 0 & $6-16$ \\
\hline M. D. & 14 & “ Normal " & $\mathbf{S}$ & $10 \cdot 7$ & 6-16 \\
\hline R. S. & 14 & Slightly tall. Normal weight & $\mathbf{S}$ & 14 & $6-16$ \\
\hline M. H. & 15 & Slightly fat. Normal weight. Slight gynaecomastia & G & $8 \cdot 0$ & $7-17$ \\
\hline B. $S$. & 15 & Normal height. Abnormally heavy & S & $7 \cdot 7$ & $7-17$ \\
\hline J. W. & 15 & "Average build." No obesity & G & $6 \cdot 3$ & $7-17$ \\
\hline G. W. & 16 & Rather short. Unusually light. "Lorain” type & G & 7 & $8-23$ \\
\hline R. K. & 16 & Normal height. Unusually light & G & $9 \cdot 1,8 \cdot 2$ & $8-23$ \\
\hline M. C. & 16 & Fat striae & G & 11 & $8-23$ \\
\hline A. McC. & 16 & Rather tall. Normal weight & G & $18 \cdot 1$ & $8-23$ \\
\hline H. O. & 17 & Normal weight. Rather thin & G & $14 \cdot 9$ & $8-23$ \\
\hline B. $\mathbf{M}$. & 18 & Seemingly normal weight and height & G & $11 \cdot 5$ & $8-23$ \\
\hline
\end{tabular}

TABLE IV

Urinary Ketosteroid EXCRETION-GirLS

\begin{tabular}{|c|c|c|c|c|c|}
\hline Patient & Age & Physique & $\begin{array}{l}\text { Type } \\
\text { of } \\
\text { slip }\end{array}$ & $\begin{array}{l}\text { Urinary ketosteroid } \\
\text { excretion } \\
\text { milligrams/24 hours }\end{array}$ & $\begin{array}{l}\text { Normal " } \\
\text { for age }\end{array}$ \\
\hline M. F. & 9 & Slightly tall. Very heavy & G & 4 & \\
\hline C. B. & 9 & Very tall. Very heavy. "Frölich" type. & G & 4 & \\
\hline I. B. & $\begin{array}{l}11 \\
12\end{array}$ & Normal & $\mathbf{S}$ & $\begin{array}{l}2 \cdot 7,3 \cdot 4 \\
5 \cdot 6,6 \cdot 4\end{array}$ & $2-11$ \\
\hline J. E. & 11 & ? Slightly overweight & G & $7 \cdot 4$ & $2-11$ \\
\hline N. C. & 11 & Slightly tall. Very heavy & G & $18 \cdot 2$ & $2-11$ \\
\hline J. C. & 11 & Rather tall. Very heavy & G & $1 \cdot 3$ & $2-11$ \\
\hline R. B. & 11 & Very tall. Very heavy & G & $19 \cdot 1$ & $2-11$ \\
\hline B. $\mathbf{H}$. & 12 & * Average & G & 3 & $2-11$ \\
\hline J. H. & 12 & Normal & $\mathbf{S}$ & $9 \cdot 3,11 \cdot 9$ & \\
\hline D. $\mathbf{L}$. & 13 & $?$ & G & $2 \cdot 4$ & \\
\hline G. F. & 13 & Slightly short. Rather fat. "Frölich type." & G & $12 \cdot 7$ & \\
\hline
\end{tabular}

* The only patient menstruating. 
TABLE V

Number of Patients With and Without Seeming Endocrine Defect

\begin{tabular}{|c|c|c|c|}
\hline & Boys & Girls & Total \\
\hline Number with presumptive evidence of endocrine defect & 11 & 20 & 31 \\
\hline Number with unusual, but not abnormal, weight & 7 & 5 & 12 \\
\hline Number constitutionally seemingly normal & 22 & 8 & 30 \\
\hline (Number not assessed) & (20) & (7) & (27) \\
\hline
\end{tabular}

TABLE VI

Possible Constitutional Factors in Bilateral and Unilateral Affection

\begin{tabular}{|c|c|c|c|c|c|c|}
\hline & & & & Bilateral & Unilateral & Total \\
\hline \multicolumn{4}{|c|}{ Presumptive endocrine defect } & 9 & 22 & 31 \\
\hline \multicolumn{4}{|c|}{ Unusual (but not abnormal) weight } & 2 & 10 & 12 \\
\hline \multicolumn{2}{|c|}{ Constitutionally normal } & - & - & 10 & 20 & 30 \\
\hline Total assessed & . & - & - & 21 & 52 & 73 \\
\hline (Not assessed) & . & . & . & (2) & (25) & (27) \\
\hline Total & . & $\cdot$ & . & 23 & 77 & 100 \\
\hline
\end{tabular}

TABLE VII

Femoral Upper Epiphysial Plates

(Unilateral cases)

\begin{tabular}{|l|l|}
\hline Side of slip & $\frac{\text { Thickened }}{42}$ \\
\hline Other side & $\frac{\text { Not thickened }}{27}$ \\
\hline
\end{tabular}

TABLE VIII

Correlation of Thickening of Epiphysial Plate With Other Evidence of Endocrine Defect

\begin{tabular}{|c|c|c|c|c|c|}
\hline $\begin{array}{l}\text { Thickened } \\
\text { plate }\end{array}$ & $\begin{array}{l}\text { Patients with } \\
\text { (other) presumptive } \\
\text { evidence of } \\
\text { endocrine defect }\end{array}$ & $\begin{array}{c}\text { Patients of } \\
\text { unusual but } \\
\text { not abnormal } \\
\text { weight }\end{array}$ & $\begin{array}{c}\text { Patients } \\
\text { constitutionally } \\
\text { seemingly } \\
\text { normal }\end{array}$ & $\begin{array}{c}\text { (Number } \\
\text { not } \\
\text { assessed) }\end{array}$ & Total \\
\hline Lower radial & $* 2$ & 1 & 2 & & 5 \\
\hline $\begin{array}{l}\text { Upper femoral opposite } \\
\text { to side of slip }\end{array}$ & 0 & 0 & 1 & (1) & 2 \\
\hline
\end{tabular}

* One “ Frölich,” one “ Lorain.” 
but in another the density was greater than in the control. Only one patient showed evidence of retardation of ossific centres. The radial epiphysial disc was thickened (usually slightly) in five, narrower than the control in one, and in twenty-one cases there was no difference. (In one case the epiphysis was excluded from the film.)

A less reliable check on epiphysial maturation generally was provided by recording whether slipping of one femoral epiphysis was accompanied by thickening of the opposite epiphysial plate. Although, in unilateral cases, the disc on the affected side was reported to be thickened much more often than not (in forty-two cases out of sixty-nine) the opposite disc was observed to be thickened only twice in fifty-three cases (Table VII). At first sight this seems inconsistent with any important endocrine (and therefore general) factor in slipping of the femoral epiphysis; but there is the possible fallacy that an increased clear band on the side of the slip may represent something more than just thickening of the disc, so that slight thickening on the seemingly normal side might be masked for want of a reliable standard for comparison.

Nevertheless the evidence is against any general thickening of epiphysial discs in most of these cases.

We have failed to find any constant relationship between thickening of the epiphysial plate of the radius or of the undisplaced femoral epiphysis and other evidence of endocrine disturbance (Table VIII).

\section{INJURY}

History of injury-The questions about injury were answered in ninety-five instances. In thirty-eight there had been a recent injury seemingly involving the hip, and in an almost equal number there had been no injury at all (Table IX).

TABLE IX

HISTORY OF INJURY

\begin{tabular}{|c|c|c|}
\hline Relevant & & \\
\hline before onset & 197 & 20 \\
\hline at onset & $19\}$ & 38 \\
\hline after onset . & 11 & \\
\hline Not relevant & 6) & 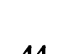 \\
\hline None & $38\}$ & 44 \\
\hline Indefinite . & 2 & \\
\hline (Unrecorded) . & $(5)$ & \\
\hline
\end{tabular}

Types of injury-The injuries were of the same type both in those who suffered a sudden epiphysial slip and in those with a gradual one. Much the commonest accident was a fall, often directly on to the affected hip, but sometimes on the thigh, knee or foot. The other common accident was a wrench. The common sources of both kinds of accident were: a variety of games; stumbling or slipping on stairs, steps or the level; and falls from bicycles.

Relation of injury to sudden or gradual epiphysial slip- In thirty patients (fourteen boys and sixteen girls) the slip seems to have occurred suddenly, but in seven (five boys and two girls) of these there had evidently been previous gradual slipping.

In fourteen patients (six boys and eight girls) the sudden slip could be called " acute "; that is to say that the patient was immediately disabled by pain and muscle spasm. In six patients (three boys and three girls) this acute slipping was preceded by symptoms of gradual slipping. In two girls, a sudden slip seemed to be followed a few days later by a further slip, 
this time acute. The former of these patients, aged thirteen, suffered initial pain and disability when she tripped and twisted her hip running, and sustained the acute slip seventeen days later stepping from a high kerb; the second, aged twelve, sustained the initial slip in a fall on the left hip and the acute slip eight days later when she tripped and twisted the hip.

TABLE X

History of InJury in Relation to Type of Slip

\begin{tabular}{|c|c|c|}
\hline & $\begin{array}{l}\text { History of seemingly } \\
\text { relevant injury }\end{array}$ & $\begin{array}{l}\text { No relevant } \\
\text { injury }\end{array}$ \\
\hline Sudden slip & 26 & 4 \\
\hline Gradual slip & 23 & 40 \\
\hline
\end{tabular}

There appeared to be a relevant injury in twenty-six (fourteen boys and twelve girls) of the thirty patients with sudden slipping; and in thirteen (seven boys and six girls) of the fourteen patients with " acute" sudden slipping.

Relation of injury to endocrine type-That most or all of these injuries were relevant there seems little doubt; the genuinely doubtful ones have been rejected. What is impossible to say is which, if any, of them would be adequate to separate a normally firm epiphysis.

TABLE XI

History of INJURy in ReLation to ENDOCRINe TyPe

\begin{tabular}{|lccc|}
\hline & $\begin{array}{c}\text { History of seemingly } \\
\text { relevant injury }\end{array}$ & $\begin{array}{c}\text { No relevant } \\
\text { injury }\end{array}$ \\
\hline Patients with seeming endocrine defects & - & 9 & 18 \\
Patients of unusual but not abnormal weight & 7 & 5 \\
Patients without evident endocrine defect &. & 11 & 23 \\
\hline
\end{tabular}

We have attempted to relate presence or absence of a history of injury with endocrine type (Table XI).

These figures do not suggest that relevant injury plays either a bigger or a smaller part in the patient with evident endocrine defect than in the patient without.

TABLE XII

ONSET OF Pain in Relation to Limp

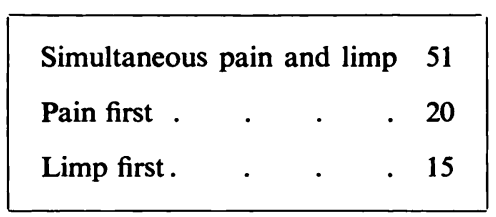

TABLE XIII

Site of ONSET of Pain

\begin{tabular}{|c|c|c|}
\hline Hip region & . & 60 \\
\hline Knee region & . & 22 \\
\hline \multicolumn{3}{|c|}{ Hip and knee simultaneously } \\
\hline
\end{tabular}

\section{CLINICAL FEATURES}

Pain and limp, the cardinal symptoms, started simultaneously in about half the recorded cases; in the rest pain preceded limp more often than vice versa (Table XII).

Contrary to text-book statements, pain began much more often about the hip than about the knee, and occasionally at both (Table XIII). 
Both pain and limp more often started gradually than suddenly. Pain was more often intermittent than continuous; limp the reverse (Table XIV).

Wasting-Surprisingly, demonstrable wasting was almost as often absent as present (Table XV). Shortening-More than half the patients presented shortening of half an inch or more, a few as much as one inch and over (Table XVI).

TABLE XIV

ONSET AND Character of Pain AND OF Limp

\begin{tabular}{|c|c|c|}
\hline & Pain & Limp \\
\hline \multicolumn{3}{|l|}{ Onset } \\
\hline Gradual & 55 & 56 \\
\hline Sudden & 31 & 18 \\
\hline \multicolumn{3}{|l|}{ Character } \\
\hline Continuous & 37 & 58 \\
\hline Intermittent & 46 & 27 \\
\hline
\end{tabular}

TABLE XV

WASTING

\begin{tabular}{|llllc|}
\hline Present & $\cdot$ & $\cdot$ & $\cdot$ & 40 \\
Absent & $\cdot$ & $\cdot$ & $\cdot$ & 39 \\
(Unrecorded) & $\cdot$ & $\cdot$ & $\cdot$ & $(21)$ \\
\hline
\end{tabular}

TABLE XVI

ReAL SHORTENING

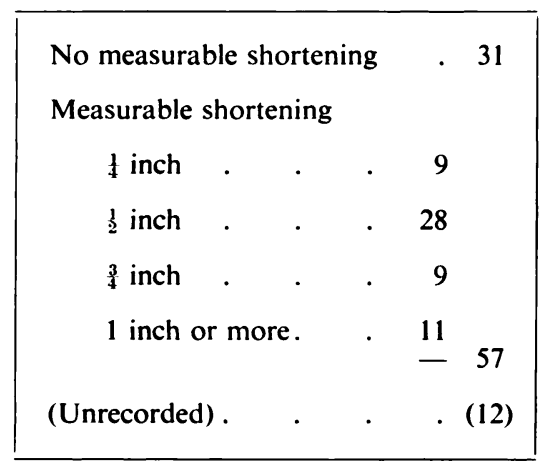

Other deformities-As usually supposed, lateral rotation was the commonest deformity, occurring in about half the cases, usually alone but sometimes combined with adduction and more rarely flexion. Adduction was found in less than a quarter of the cases, nearly always in combination with lateral rotation deformity. Contrary to text-book teaching flexion deformity was sometimes found, but almost never alone (Table XVII).

Stiffness-Limitation of movement has been classified into slight, moderate and great by a thoroughly unmathematical method that proved unexpectedly easy to apply. Slight implies 
the small limitation that a specialist should detect but that a well-trained but unaccustomed general man could pardonably miss. Moderate stiffness implies substantial limitation of several movements that any decently trained practitioner should detect. Great stiffness implies a negligible range or near it (Table XVIII).

TABLE XVII

DEFORMITY

\begin{tabular}{|c|c|c|c|}
\hline & Lateral rotation & Adduction & Flexion \\
\hline Alone & 33 & 1 & 1 \\
\hline With lateral rotation only. & - & 14 & 2 \\
\hline With adduction only & 14 & - & 3 \\
\hline With flexion only & 2 & 3 & - \\
\hline $\begin{array}{l}\text { Part of rotation, adduction, } \\
\text { flexion deformity }\end{array}$ & 5 & 5 & 5 \\
\hline Total & 54 & 23 & 11 \\
\hline
\end{tabular}

TABLE XVIII

Limitation of Hip MOVEMENT

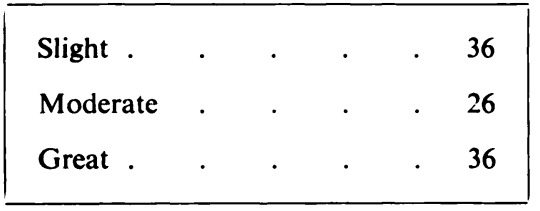

TABLE XIX

Extent of Displacement, as SEen in ANTERo-Posterior and Lateral Views, in Relation to Evidence of NeCrosis

\begin{tabular}{|c|c|c|c|c|}
\hline \multirow{2}{*}{ Displacement } & \multicolumn{2}{|c|}{ Antero-posterior view } & \multicolumn{2}{|c|}{ Lateral view } \\
\hline & Number & Necrosis & Number & Necrosis \\
\hline Minimal & 37 & 2 & 24 & 1 \\
\hline Quarter diameter. & 21 & 1 & 25 & 1 \\
\hline Half diameter & 21 & 1 & 27 & 1 \\
\hline Three-quarters diameter & 7 & 1 & 5 & 1 \\
\hline Whole diameter & 7 & 0 & 7 & 0 \\
\hline Totals & 93 & 5 & 88 & 4 \\
\hline
\end{tabular}

\section{RADIOGRAPHY}

The epiphysial plate of the affected femoral epiphysis appeared thickened in rather more than half the cases in which its appearance was reported. Contrary to expectation the opposite plate, in unilateral cases, has only occasionally been demonstrably thickened.

In agreement with common supposition, displacement of the epiphysis has tended to be rather more evident in lateral than in antero-posterior films. 
Radiological evidence of avascular necrosis was exceptional at the time of first examination and seemed unrelated to the extent of slip (Table XIX), but no deduction can be made because radiological diagnosis of avascular necrosis in the early months is unreliable.

The probable duration of symptoms before observation in the five cases in which there was initial radiographic evidence of necrosis was: six weeks, four months, four months, five months and a year. In two there was no injury; in one an injury preceded symptoms; in another it coincided with slipping; and in another it followed them. Slipping occurred gradually in three of the cases and suddenly in two.

\section{DELAY IN TREATMENT}

The ease of treatment, and almost certainly its results, depend so much upon early treatment that an investigation of the causes of delay seemed appropriate.

Definition-We have considered that there was delay if more than one month elapsed between the time that the symptoms began and the time that medical advice was sought, or if more than a month elapsed between the time advice was sought and the time efficient treatment began. Causes of delay were: 1) parental procrastination; 2) diagnostic failure; 3) administrative failure; and 4) shortage of accommodation.

Parental procrastination caused delay of one and a half, two, two, three, five, five, seven and twelve months. The reason was often uncertain. The usual explanation offered was either that the condition seemed trivial or that it was ascribed to " rheumatism " and therefore accepted as a necessary evil. Certainly parental delay was confined to cases of gradual slipping. An only child was the victim of an over-solicitous mother who sought multitudinous advice and accepted none.

Diagnostic failure seems to have been responsible for delay of two to eighteen months in nineteen cases. In five (six weeks to one year, including a delay of four months in a patient in hospital for plastic surgery) no diagnosis seems to have been made. What is almost the same thing-a diagnosis of " rheumatism " was made in five cases, with delays of two, three, seven, twelve and fifteen months. Delays of one month, four months and one year were accounted for by diagnosis of muscle injury. In three cases attention was directed to the knee, to the exclusion of the hip, for five, ten and twelve months. Failure to detect radiological changes involved delay of four months, five months and eighteen months in three cases (Table XX).

TABLE XX

Diagnostic failures Causing Delay in Treatment

\begin{tabular}{|lccc|}
\hline \multicolumn{1}{|c}{ Failure } & & Number of cases & Delay (months) \\
\hline No diagnosis made. &. & 5 & $1 \frac{1}{2}, 4,6,9$ and 12 \\
Diagnosis of "rheumatism" &. & 5 & $2,3,7,12$ and 15 \\
Diagnosis of muscle injury &. & 3 & 1,4 and 12 \\
Wrong joint (knee) suspect &. & 3 & 5,10 and 12 \\
Radiological changes undetected & 3 & 4,5 and 18 \\
\hline
\end{tabular}

These depressing figures should be considered against the promptness in dealing with four-fifths of the cases and the deplorable conditions of overwork, inadequate assistance, overcrowding and obsolete accommodation under which much "Health Service" practice is conducted at present.

Administrative failures-Bad organisation and clerical errors accounted for delays of five weeks, six weeks and four months. 
Shortage of accommodation-Four patients had to wait two months, two months, six months and eight months simply because beds could not be found for them.

\section{SOME MISCELLANEOUS, PROBABLY IRRELEVANT, INVESTIGATIONS}

The erythrocyte sedimentation rate was normal (equivalent to less than 10 millimetres/ 1 hour by Westergren method) in eleven cases, slightly raised (10-19 millimetres) in three cases and moderately raised (20-33 millimetres) in five cases.

The Wassermann (or equivalent) test was negative in the sixteen cases in which it was done.

With possibly one exception, the blood calcium and phosphorus were normal in the eight cases so investigated. The alkaline phosphatase was normal in three cases and raised to 18.0 phenol units (normal 5-15) in one.

\section{CASES OF SPECIAL INTEREST NOT IN THE SERIES}

Case 1, in pituitary giantess (Mr R. J. W. Withers's patient)-A girl of fourteen years, a sample-maker, was thin but 5 feet $11 \frac{1}{2}$ inches tall, was without dietetic fads and had not begun to menstruate. Soon after hospital investigation for pituitary disorder she complained of pain in the right knee for three weeks and in the right hip for a few days. She presented 60 degrees lateral rotation deformity of the right hip, with great restriction of all its movements. Radiographs showed slipping of the femoral epiphysis (a quarter circumference in antero-posterior view, a quarter to a half in lateral view) without evident thickening of the disc. She was treated by traction for three months and by caliper for six months till epiphysial fusion began, without further slipping. Twenty-two months from the onset she had no symptoms and an almost full range of movement, and she was 6 feet 3 inches tall.

Case 2, in pituitary hypogonadism: slipped upper femoral epiphysis at the age of thirty-three years-An unmarried medical librarian, aged thirty-three, a victim of hypogonadism, fell heavily from a bicycle on to his right knee. He had no pain till, two hours later, on rising from sitting, he could hardly bear weight on his right leg because of pain in the right hip. Nevertheless he went on a cycling holiday, but increasing pain and limp caused his admission to hospital seven months later, where the hip was treated by weight traction and then a walking caliper, and he received testosterone for six to eight months. Eight years later there was an inch of real shortening above the trochanter and 45 degrees of lateral rotation deformity of the hip; except for absence of medial rotation and abduction, movements were almost full. Radiographs confirmed old slipping of the upper femoral epiphysis (about a quarter of its circumference as seen from in front). The epiphyses at the upper ends of the femora had united, the lower only just; the lower radial and ulnar epiphysial plates were still open, but those of the metacarpals and phalanges had fused. The patient was 5 feet 5 inches in height and weighed 8 stones $5 \mathrm{lb}$. (117 lb. $=53$ kilograms) clad. His testes were descended but small. His skin was dry, his face wrinkled and sallow, and he was almost hairless except on the scalp. His voice was normal. Further investigation was inopportune.

Case 3, with infantile paralysis of the opposite limb (Mr K. I. Nissen's patient)-A boy of fourteen years had suffered severe poliomyelitis affecting most of the right lower limb except the hip, but with little residual paralysis except in calf and foot, which presented talipes calcaneo-cavo-valgus. The left lower limb was seemingly unaffected, but a slip on stairs gave sudden pain in the left groin. Four days later all movements of the left hip were painful and it presented 45 degrees lateral rotation deformity. Radiography showed, in both antero-posterior and lateral views, slipping of the femoral epiphysis through half its diameter; the epiphysial disc appeared thickened on the left only, and the density of the head was not then increased. Almost complete reduction by nine days' traction with 15 pounds, and then nail fixation, were followed within three months by increasing density of the head and later deformity of avascular necrosis. The patient was tall ( 5 feet $8 \frac{1}{2}$ inches) but of normal weight ( 7 stones $12 \mathrm{lb} .=110 \mathrm{lb} .=50$ kilograms) for his age, normally developed, showed some general osteoporosis and had a urinary excretion of 17 -ketosteroids of 9 milligrams/24 hours.

Case 4, with Legg-Calvé-Perthes disease of the opposite hip ( $\mathrm{Mr} \mathrm{R}$. W. Butler's patient)-A boy of seventeen, who had Legg-Calvé-Perthes disease of the right hip at the age of ten with little subsequent disability except limitation of rotation, suffered a slight twist of the left hip at the age of sixteen, followed by the gradual onset of constant aching pain which became suddenly worse seventeen months later, when the left hip showed lateral rotation deformity and poor movement. Radiographs revealed slipping of the upper femoral epiphysis amounting to a quarter of its diameter in the antero-posterior view and a half of its diameter in the lateral view. Manipulation and nailing gave a good result without evidence of avascular necrosis in the next ten months. The patient was fat, but normally developed. 
Cases 5 and 6 in brothers (Mr R. W. Butler's patients)-A boy aged seventeen had suffered for six months from an intermittent pain in the left hip and limp of gradual spontaneous onset. Full flexion and extension were preserved, but medial rotation and abduction were totally abolished, and adduction and lateral rotation were halved. There was half an inch of real shortening and half an inch of thigh wasting. Antero-posterior and lateral radiographs showed slipping of the upper femoral epiphysis through a quarter of its diameter. A basal osteotomy with nailing gave, seven months later, a full range of painless movement, and the epiphysis had fused.

A month after this boy reported, his brother aged fifteen gradually began to suffer pain in the left knee. The hip showed the same radiographic abnormality as his brother's, but, presenting only four weeks' history, was treated by manipulation and a hip spica for three months. Nine months after the onset he had an excellent result with the epiphysis viable and fused.

\section{SUMMARY}

1. By questionnaire, an attempt has been made to ascertain the characteristics of a hundred cases of slipping of the upper femoral epiphysis.

2. The principal object has been to see whether an etiological classification would be possible pending an assessment of the results of treatment.

3. Proper statistical analysis has proved impossible because of the incompleteness of the data.

4. As usual, boys predominated and were usually affected as much as three years older than the girls.

5. It was exceptional to find epiphysial slipping in a girl once she had begun to menstruate.

6. Nearly a quarter of the cases were bilateral, or became so after six to twenty-four months or more.

7. Little information came from an enquiry about dietary fads, the estimation of urinary ketosteroid excretion in twenty-three of the patients, or some minor pathological investigations. 8. No convincing evidence was found of skeletal retardation or of general thickening of epiphysial discs, such as might perhaps be expected in a hormonal disturbance characterised by defective epiphysial maturation.

9. From each child with the necessary data, indices of height, weight and build were ascertained, which would indicate his expectation of finding a place among a hundred physically normal children of his own sex and age, and, if so, where that place would be. From these studies four groups of children seemed to emerge: 1 ) what may be called abnormally heavy children who would not find a place among a hundred, or somestimes a thousand, physically " normal" children of their own age and sex; 2) unusually heavy children who would find a place in the heaviest minority of the normal hundred; 3 ) a very small group of abnormally small people, among whom might be expected the subjects of pituitary infantilism; and 4) a large group of children of average physique for their sex and age.

10. From this information and from clinical evidence in the case returns, it appeared that a quarter of the assessable boys and nearly two-thirds of the assessable girls showed evidence of endocrine defect, quite apart from those who were merely unusually fat.

11. By distinguishing these two groups of children from a third group of constitutionally " normal," an attempt has been made to see whether there is any correlation between evident endocrine defect and such characteristics as bilateral affection, delayed epiphysial maturation, a history of relevant injury and its nature, and sudden or gradual epiphysial slipping.

12. No relationship was established between any of these characteristics and endocrine type: bilateral affection was no commoner in the endocrine group; delayed maturation was not demonstrated in either; a history of relevant injury was equally common, and its nature identical, in both; slipping might be sudden or gradual in either indiscriminately.

13. There was a history of seemingly relevant injury in half the patients, and it was much commoner with sudden slipping than with gradual slipping. Sudden slipping was often preceded by symptoms of gradual slipping, or sudden slipping of one epiphysis was sometimes followed by gradual slipping of the other.

VOL. 39 B, NO. 4, NOVEMBER 1957 
14. In gradual slipping the cardinal symptoms were pain and limp, usually starting synchronously and gradually; the pain was usually intermittent and referred much more often to the hip than the knee; the limp was usually continuous.

15. Of signs, demonstrable wasting seemed to be absent as often as present, but shortening was usual. Lateral rotation deformity was usually present, adduction often, and flexion sometimes. In more than a third of the cases limitation of movement was slight enough to be easily missed.

16. The radiographic observations confirmed the seeming widening at the affected epiphysial disc, the greater displacement revealed by the lateral view, and the difficulty of identifying avascular necrosis before collapse.

17. Treatment was delayed in thirty-four cases-a third of the whole; the reasons have been analysed; diagnostic failure was the cause in nineteen.

18. A few cases outside the series have been mentioned briefly because of special points of interest : slipping in gross pituitary disease-in pituitary giantism, and (at the age of thirty-three) in pituitary hypogonadism; slipping with defect of the opposite lower limb-infantile paralysis of the leg, and Legg-Calvé-Perthes disease of the hip; familial affection-slipping in two brothers.

19. The results of treatment in the present cases, supplemented by others, have been studied by Dr John Hall and related to some of the clinical features. His paper appears separately.

\section{PRINCIPAL CONCLUSION}

An extensive study of a hundred cases of adolescent slipping of the upper femoral epiphysis has failed to demonstrate any fundamental difference in behaviour between those with manifest endocrine defects and those without. Consequently, and contrary to expectation, no classification based on the natural history of different groups has been possible.

The following surgeons, with their assistants, have kindly provided the material for this investigation and have given Mr John Hall every facility for follow-up. Aberdeen, Mr A. M. Rennie; Bath, Miss M. F. Forrester-Brown; Belfast, Dr H. P. Hall, Mr N. S. Martin, Mr R. J. W. Withers ; Cambridge, Mr R. W. Butler, Mr T. J. Fairbank; Canterbury, Mr F. G. St C. Strange; Carshalton, Mr R. H. Metcalfe, Mr R. G. Thomas; Derby, Mr R. G. Pulvertaft; Glasgow, Mr R. Barnes, Mr R. D. Muckart; Hairmyres, Mr R. N. Traquair; Leeds, Mr R. Broomhead, Mr A. B. Pain, Mr T. Price; Liverpool, Mr P. B. Moroney, Mr R. F. O’Driscoll, Mr A. G. O’Malley, Mr N. W. Roberts, Mr E. N. Wardle; London, Mr J. S. Batchelor, Mr J. G. Bonnin, Mr B. H. Burns, Mr W. D. Coltart, Mr S. L. Higgs, Mr J. I. P. James, Mr P. H. Newman, Mr K. I. Nissen, Mr R. Y. Paton, Mr H. J. Seddon, Mr D. Trevor; Manchester, Mr S. M. Milner; Nottingham, Mr S. A. S. Malkin; Oxford, Mr W. B. Foley; Windsor, Mr G. P. Arden.

To all these, and especially to Dr John Hall, Mr E. N. Wardle and Dr A. McPherson, the collator is deeply indebted.

\section{REFERENCES}

Harris, W. R. (1950): The Endocrine Basis for Slipping of the Upper Femoral Epiphysis. An Experimental Study. Journal of Bone and Jomt Surgery, 32-B, 5.

Sl:cliffe, A., and CanhaM, J. W. (1950): The Heights and Weights of Boys and Girls. London: John Murray. 